\title{
BLOOD BORNE VIRUSES IN CORRECTIONAL FACILITIES
}

\section{Cate Wallace}

NSW Public Health Officer Training Program

NSW Department of Health

\section{Sue Hailstone}

Centre for Drug and Alcohol

NSW Department of Health

\section{Prof Andrew Lloyd \\ Faculty of Medicine \\ University of New South Wales}

Blood borne viruses (BBVs) are viruses that are transmitted by blood or body fluids containing blood. The most important BBVs in Australia include hepatitis C (HCV), hepatitis B (HBV) and human immunodeficiency virus (HIV). The August 2005 Bug Breakfast explored the prevalence of BBVs in people entering prison, BBV-related risk behaviours in prisons, and existing harm reduction strategies in correctional facilities.

\section{THE PRISON CONTEXT}

Approximately 24,000 people move through the NSW correctional system each year, the majority (90 per cent) serving sentences of less than six months. These inmates experience a disproportionate burden of health problems, including mental health disorders, substance use, sexually transmitted infections and BBVs. Inmates are more likely than the general population to be Aboriginal and to have histories of poor educational attainment and unemployment. In correctional facilities in NSW both Justice Health and the Department of Corrective Services provide programs designed to prevent $\mathrm{BBV}$ transmission.

\section{PREVALENCE OF BBVS AMONG AUSTRALIAN PRISON ENTRANTS}

The National Prison Entrants' Bloodborne Virus Survey was the first nationally coordinated survey of prisoners undertaken in Australia. ${ }^{1}$ A consecutive cross section of prison entrants was taken over two weeks in May 2004. Participants were 612 of the 739 individuals entering eight reception prisons in NSW, Queensland, Tasmania and Western Australia.

Voluntary confidential testing for markers of exposure to HIV, HCV and HBV was conducted on all prison entrants who participated in the study. The study was modelled on the national Needle and Syringe Program Survey (NSPS), a community survey of needle exchange attendees. Demographic data and data related to risks for

*Bug Breakfast is the name given to a monthly series of hour-long breakfast seminars on communicable diseases delivered by the NSW Department of Health's Division of Population Health.
BBV transmission, including sexual activity, body piercing, tattooing and injecting drug use, were collected.

The response rate was high for both the questionnaire (77 per cent) and the blood testing (63 per cent) components of the study. The overall prevalence of HIV, HBV core antibody, and HCV antibody in the sample was less than one per cent, 20 per cent and 35 per cent respectively. Among injecting drug users the prevalence for HIV, HBV core antibody, and HCV antibody was less than one per cent, nine per cent and 56 per cent respectively. The prevalence of HIV among prison entrants is low and is consistent with the findings of the NSPS; HCV prevalence is also consistent with the findings of the NSPS. The proportion of inmates who had been previously vaccinated against HBV varied across correctional jurisdictions.

Fifty nine per cent of those screened reported injecting drugs in their lifetime. Of these, 65 per cent reported injecting in the month prior to entering prison. Nationally, the most frequently reported drugs to be last injected were amphetamines ( 55 per cent), but in NSW heroin was the drug most frequently reported as last injected ( 52 per cent).

The National Prison Entrants' Bloodborne Virus Survey collected data from twice the proportion of Indigenous Australians as compared to the NSPS, and allows for greater surveillance of BBVs among this population. The survey of prison entrants also provides information on non-injecting drug users who may be at risk of BBV infection. This survey is an adjunct to the NSPS and significantly enhances current national surveillance of BBVs.

\section{BBV-RELATED RISK BEHAVIOURS}

Prisons are a high-risk environment for BBV transmission due to the relatively higher prevalence of these infections among prison entrants and the large proportion of inmates who report engaging in behaviours conducive to the transmission of BBVs, including injecting drug use (IDU), non-sterile tattooing, skin piercing, physical violence, self-harm, unprotected sex, recreational sport and prison employment. ${ }^{2}$

A significant number of inmates inject drugs while in prison. Of the 73 per cent of female and 53 per cent of male inmates who report a history of injecting drug use, 62 per cent of female and 48 per cent of male inmates continue to inject while in prison. Of these, 70 per cent reuse syringes and over 30 per cent report sharing syringes with five or more inmates per injection. ${ }^{3}$ Sharing of other injecting equipment (spoons, water, filters and tourniquet) also occurs. HIV transmission via IDU has been confirmed in at least two Australian prison studies. ${ }^{4,5}$ 
Prison tattooing with non-sterile equipment is common; approximately 40 per cent of inmates receive a tattoo while in prison. ${ }^{6}$ Prison tattooing is an independent risk factor for $\mathrm{HBV}$ and $\mathrm{HCV}$ infection in inmates who have never injected drugs. ${ }^{6}$

Unsafe sex places inmates at a heightened risk of contracting sexually transmitted infections and HIV. The risk is heightened in sexual assaults. ${ }^{3}$ Evidence suggests that a proportion of prisoners engage in consensual sexual activity in prison. Twenty three per cent of women and three per cent of men report engaging in sexual activities in prison and 23 per cent of women and 15 per cent of men report being aware of sexual assaults occurring in prison in the previous twelve months. ${ }^{3}$ These figures may underestimate the true frequency.

Prison assaults and self-harm are situations where inmates and correctional staff may come into contact with blood through direct involvement, by being a bystander or through cleaning up blood spills afterwards. ${ }^{2}$

Recreational sport and prison employment are activities that have been associated with exposure to blood. One Australian survey reported that 18 per cent of inmates were exposed to blood while engaging in recreational activities and 25 per cent reported workplace exposures to blood. ${ }^{2}$

\section{EXISTING HARM MINIMISATION STRATEGIES}

A range of existing harm minimisation strategies are currently in place in NSW correctional facilities. These include the provision of treatment for drug dependence; BBV education, screening, counselling and treatment; the provision of bleach to clean injecting equipment; provision of condoms and lubricant to encourage safe sex; HBV vaccination; and HBV and HIV post exposure prophylaxis. At present professional tattooing and piercing and needle and syringe programs are not available in NSW prisons.

\section{CONCLUSION}

Prisoners experience a disproportionate burden of health problems; they have a high prevalence of BBVs and many engage in high-risk behaviours for BBV transmission. Highrisk behaviour is not, however, random, uncontrollable or inevitable. BBV transmission is preventable. Many factors that contribute to an individual's propensity to engage in high-risk behaviours for BBVs transmission can be modified and lasting changes can result from targeted and persistent harm reduction initiatives.

\section{REFERENCES}

1. Butler T, Boonwaat L, Hailstone S. National prison entrants' bloodborne virus survey, 2004. Sydney: Centre for Health Research in Criminal Justice \& National Centre in HIV Epidemiology and Clinical Research, University of New South Wales, 2005.

2. Heale P, Wallis J, Swan A, Alberti S. Survey of harms in Victorian prisons. Melbourne: Turning point Alcohol and Drug Centre Inc, 2003.

3. Butler T, Milner L. The 2001 New South Wales inmate health survey, Sydney, Corrections Health Service, 2003.

4. Dolan, K \& Wodak, A. HIV transmission in a prison system in an Australian state. MJA 1999; 171: 14-17.

5. Dolan K, Wodak A, Hall W, Gaughwin M, Rae F. HIV risk behaviour of IDUs before, during and after imprisonment in New South Wales. Addiction Research 1996; 4(2): 151-60.

6. Post J, Dolan K, Whybin L, Carter I, Haber P, Lloyd A. Acute hepatitis $\mathrm{C}$ virus infection in an Australian prison inmate: tattooing as a possible transmission route, MJA 2001; 174: 183-4. 중 